\title{
DIE INDIVIDUALISERING VAN ORGANISASIES: EDWARD E. LAWLER III SE BYDRAE TOT DIE BEDRYFS-ORGANISASIE SIELKUNDE
}

\author{
*L.D. COETSEE \\ DEPARTEMENT BEDRYFSIELKUNDE \\ UNIVERSITEIT VAN SUID-AFRIKA
}

\begin{abstract}
SUMMARY
Lawler's research publications over a large number of topics. His primary scientific interest, however, is job motivation and how it influences human behaviour in the world of work. Lawler emphasizes that the causes of motivational and job dissatisfaction problems are rooted in the fact that organizations are designed for the hypothetical "average person" and that any given labour force possess few, if any, average persons. The various methods which Lawler proposes to individualize organizations are described in this article. It includes new views and recommendations regarding topics such as rewards and fringe benefits, selection, job design and job enlargement, leadership, hours of work and training.
\end{abstract}

As die literatuur oor organisasieteorie en -navorsing nagegaan word, val dit op dat sielkundiges se belangstelling hierin, in teenstelling met ander sosiale wetenskaplikes, slegs oor die afgelope twee dekades waarneembaar is. Die ontwikkeling van die sogenaamde moderne organisasieteorie deur veral Likert, Haire, McGregor en Argyris het getoon dat sielkundiges baie by te dra het tot die uitbreiding van kennis oor organisasies. Waar die klassieke organisasie-teoretici hulle veral besig hou met die strukturele aspekte van organisasies, het die moderne skool die aandag gevestig op die individu en groepe in organisasies en het hul in 'n groot mate die strukturele veranderlikes oor die hoof gesien.

Gedurende die afgelope paar jaar het bedryfs-organisasiesielkundiges in 'n toenemende mate begin besef dat mense en organisasies nie onafhanklik van mekaar bestudeer behoort te word nie. Die humanisering, demokratisering of individualisering van organisasies is ' $n$ onderwerp wat teenwoordig as gevolg van die hernude belangstelling in werktevredenheid, heelwat aandag geniet.

\footnotetext{
* Die skrywer het gedurende September 1975 tot April 1976, met behulp van 'n R.G.N.-beurs 'n studietydperk by die Institute for Social Researah, Univesity of Michigan deurgebring waar dr. Lawler professor in sielkunde en programdirekteur van organisasiesielkunde is. Die skrywer het die geleentheid gehad om o.a. 'n intensiewe studie van Lawler se werk te maak.
} 
Edward Lawler is vandag een van die bekendste organisasiesielkundiges en 'n gesogte bedryfskonsultant in die Verenigde State van Amerika en het oor die afgelope twaalf jaar aktief navorsing gedoen oor hoe om sake- en bedryfsorganisasies te individualiseer. Sy navorsing verteenwoordig van die interessantste pogings om die klassieke en moderne organisasieteorieë sinvol met mekaar in verband te bring.

Die doel van die artikel is om Lawler se werk beter bekend te stel, nie alleen omdat sy navorsing steeds die werk en denke van soveel ander navorsers beïnvloed nie, maar omdat van sy gedagtes sekerlik met vrug ook in Suid-Afrikaanse organisasies geïmplementeer kan word.

Lawler is sedert 1963 die outeur en mede-outeur van 66 artikels (wat verskyn het in van die bekendste gedragswetenskaplike tydskrifte), van ses hoofstukke in bekende handboeke en vyf boeke waarvan een (Lawler, 1971b) o.m. in Japannees vertaal is. Verskeie toekennings is aan hom gemaak vir sy navorsing en publikasies, byvoorbeeld van die McKinsey Foundation Board (1968) vir sy artikel (Lawler, 1969) oor die vergoeding van bestuurders, die Distinguished Scientific Award (1972) toegeken deur die American Compensation Association en in dieselfde jaar die gesogte Book of the Year Award, van die American College of Hospital Administrators.

Verskeie persone het 'n groot invloed uitgeoefen op Lawler se werk. Die belangrikste is miskien Edwin E. Ghiselli, Mason Haire en Lyman W. Porter. Daar is al na Lawler verwys as Porter se belangrikste bydrae tot die bedryfs-organisasiesielkunde. Hy het dan ook, met Porter as mede-outeur, heelwat gepubliseer o.m. Porter en Lawler, 1964, 1965, 1968a, 1968b en Lawler en Porter 1963, 1966, 1967,1968. Hul jongste boek, geskryf saam met Richard Hackman (Porter, Lawler en Hackman, 1975) is deur 'n resensent in American Scientist, (Julie 1975) beskryf as die eerste belangrike ("major") handboek op die gebied van organisasie gedrag.

Lawler se navorsingspublikasies dek 'n wye veld, bv. 'n ontleding van watter outeurs in 'n aantal geselekteerde psigologiese tydskrifte - aangehaal word en hoe oud hierdie aanhalings is (Lawler, 1963 en Lawler en Carol O. Lawler, 1965), 'n artikel (Lawler, 1965a) oor die sekondêre versterkingswaarde van stimuli geassosieer met skokvermindering, 'n artikel (Carol O. Lawler en Lawler, 1965) oor kleur-stemming assosiasie by klein kinders en artikels in verband met die opleiding van bedryfsielkundiges (Lawler; 1967a en 1971a). Sy primêre wetenskaplike belangstelling was egter deurgaans werkmotivering en hoe dit menslike gedrag in die werksomgewing - veral tevredenheid en prestasie - beïnvloed. Meeste 
van sy navorsing het dan ook te make gehad met verskynsels soos werkontwerp, werkverruiming, vergoeding, leierskap, opleiding en keuring wat almal direk of indirek 'n invloed mag hê op werkmotivering. Hy beklemtoon steeds dat van die oorsake van motiverings- en werkontevredenheidprobleme daarin geleë is dat organisasies ontwerp is vir die "gemiddelde mens", dat daar binne enige gegewe arbeidsmag baie min, indien enige, "gemiddelde mense" bestaan en dat hy oortuig is daarvan dat van die genoemde probleme verminder kan word deur pogings om organisasies te individualiseer. Die standpunt is gebaseer op gesonde sielkundige teorieë en soliede navorsing wat Lawler en sy medewerkers onderneem het. Dit sluit navorsing in oor verwagtingsteorie (Lawler, 1967; Lawler, 1968a; Lawler en Suttle, 1973; Lawler, Kuleck, Rhode en Sorenson, 1975); die sogenaamde billikheids- ("equity") teorie (Lawler en O'Gara, 1967; Lawler 1968b; 1968c; Wood en Lawler, 1970); die teorie dat taakprestasie 'n funksie is van inspanning, vermoë en rolpersepsie (Lawler en Porter, 1967b); werkprestasie as 'n funksie van vermoëns x motivering, (Lawler, 1966a); die verhouding tussen werkprestasie en werktevredenheid as synde daarin geleë dat prestasie lei tot beloning en beloning tot tevredenheid (Lawler en Porter, 1967a en Porter,1967a en Porter en Lawler, 1968a); faktore wat tevredenheid met salaris beïnvloed (Lawler, 1966); die motiveringswaarde van geld (Lawler, 1966b en 1967b); die gevolge van werknemerdeelname in die ontwerp van vergoedingsplanne (Lawler en Hackman, 1969 en Scheflen, Lawler en Hackman, 1971); die gevolge van die praktyk van salarisgeheimhouding (Lawler, 1965b; 1967c en 1972) en werkverruiming ('n oorkoepelende begrip vir werkvergroting en werkverryking) (Lawler, Hackman en Kaufman, 1973).

Op grond van sy wye en intensiewe navorsing kon Lawler te voorskyn kom met ingrypende nuwe voorstelle wat steun bied aan sy gedagtes oor metodes om organisasies te individualiseer. Sy menings hieroor is uiteengesit in die volgende artikels, Lawler, 1973; 1974a; 1974b; en wat nou volg is 'n kort samevatting van sommige van sy belangrikste voorstelle.

\section{Vergoeding en byvoordele}

Meeste hedendaagse organisasies het gestandaardiseerde byvoordeleskemas wat dieselfde voordele aan alle werknemers van die organisasie bied, ongeag individuele verskille met betrekking tot huwelikstatus, aantal afhanklikes, ouderdom, opleiding en persoonlike voorkeure. Die skemas is ontwerp vir die hipotetiese gemiddelde mens. Navorsing dui daarop dat byvoordeleskemas wat deur die meeste organisasies aangebied word, die goedkeuring van 
slegs $10 \%$ van hul werknemers wegdra. Negentig persent van die werknemers sou ander byvoordele gekies het as hulle die geleentheid daartoe gehad het.

Lawler se navorsing dui daarop dat byvoordeleskemas so ontwerp kan word dat dit individuele behoeftebevrediging kan verhoog. Dit kan bereik word deur byvoorbeeld die instelling van die sogenaamde kafeteriaplan. Die kafeteriaplan kan verskillende vorms aanneem, maar bestaan basies daaruit dat individuele werknemers die geleentheid kry om self te bepaal hoe hulle totale vergoeding, d.w.s. hulle normale salaris plus die geld wat die organisasie namens hulle aan byvoordele bestee, verdeel moet word tussen die kontantbedrag wat hulle as salaris wil ontvang en die geld wat aan grensvoordele van hul keuse bestee moet word. Werknemers moet van tyd tot tyd die geleentheid kry om hul keuses te hersien ten einde aan te pas by veranderde omstandighede. Die voordele verbonde hieraan is duidelik. Die organisasie bestee niks meer as voorheen aan die besoldiging van sy werknemers nie. Alhoewel die aanvanklike instelling van die plan geringe kostes mag meebring, behoort die latere voordele wat voortspruit uit verhoogde werknemertevredenheid dit uit te kanselleer. Dit is veral die werknemer wat hierby baat. Hulle voel dat hulle meer betaal word omdat hulle nou vir die eerste keer weet hoeveel die organisasie aan hulle individueel bestee. Verder kry hulle nou slegs daardie byvoordele waaraan hulle waarde heg.

Navorsing dui daarop dat as werknemers die geleentheid gebied word om die tipe besluite oor hulle eie vergoeding te neem, die oorgrote meerderheid verantwoordelike besluite neem. Ouer mense belê meer in aftrede en jong mense met families in mediese voordele. Die bevindings is ' $n$ weerspreking van die heersende gedagte dat werknemers onwyse besluite sal neem en dat die organisasie hulle moet beskerm.

Daar bestaan natuurlik 'n aantal tegniese probleme wat vooraf opgelos moet word ten einde die kafeteriaplan suksesvol te loods. Dit behels o.m. die uitwerk van die plan - definitief nie 'n eenvoudige taak nie - en verskeie probleme rakende belasting en versekering. Lawler en ander navorsers se ondervinding dui egter daarop dat die probleme te bowe gekom kan word en dat dit die moeite loon om dit te doen weens die voordele wat die kafeteriaplan meebring.

'n Ander metode waarmee Lawler en van sy medewerkers geëksperimenteer het om organisasies te individualiseer, en wat bemoedigende resultate gelewer het, is om in plaas van om die individu te betaal vir die bepaalde pos wat hy beklee, hom liewer te vergoed vir sy vermoëns en vaardighede. Anders gestel: die organisasie betaal 'n werknemer vir die aantal werksoorte wat hy kan doen, of die aantal poste wat hy in die organisasie kan beklee, in plaas 
van om hom te betaal vir die werk wat hy oor 'n bepaalde tydsverloop gedoen het. Volgens die plan kan werknemers hul salarisse verhoog deur meer werksoorte aan te leer.

'n Voorvereiste hier is 'n aktiewe werkrotasie en opleidingsplan. Die voordele hieraan verbonde is dat individue voel dat hulle regverdiger behandel word omdat hulle individuele vaardighede en vermoëns belangrik geag word en hulle beloon word vir hul vaardighede en vermoëns en vir die nuwes wat hulle mag ontwikkel. Die organisasie beskik nou oor 'n veel veelsydiger werkerskorps, kan dus baie makliker aanpas by veranderende markvereistes en kan probleme soos afwesigheid en arbeidsomset (wat steeds verantwoordelik is vir groot bedryfsverliese) meer doeltreffend die hoof bied.

\section{'n Nuwe benadering tot keuring}

Die keuringsprogramme van meeste organisasies vandag berus op o.m. die volgende aannames:

- $\quad$ mense is in so 'n mate eenders dat dieselfde keuringsinstrumente vir almal gebruik kan word

- die organisasie is beter in staat om te bepaal watter tipe organisasie-situasie (d.w.s. werk) die beste is vir individue

- $\quad$ vermoëns en vaardighede is die belangrikste faktore in die voorspelling van beroepsukses.

Eersgenoemde aanname sou nie 'n ernstige probleem gewees het as individuele verskille-faktore nie verband gehou het met die vermoë van keuringsinstrumente om prestasie te voorspel nie. Resente navorsing toon dat daar wel so 'n verband bestaan. Sekere soorte toetse het veel hoër geldigheid vir sekere populasie segmente as vir ander.

Ten opsigte van die tweede aanname meen Lawler dat individue in baie gevalle self veel beter in staat is om te bepaal by watter bepaalde pos hulle sal aanpas en watter poste hul bepaalde behoeftes sal bevredig. Die voorvereiste hier is dat die organisasie geldige data aan voornemende werknemers moet gee met betrekking tot faktore soos organisasie klimaat, werksbeskrywing, leierskapstyle, resultate van werknemertevredenheidsopnames, werknemerbeskrywings van toesighouers, data oor omset en griewe probleme, die kognitiewe en fisiese vereistes van die werk en die applikant se eie psigologiese toetsdata. Navorsing dui daarop dat as individue genoegsame inligting oor werk kry, asook die geleentheid om self te bepaal of hulle die werk sal kan doen en of die werk by hul behoeftestruktuur sal aanpas, 
hulle goeie besluite neem. Werknemers blyk dan ook minder geneig te wees om te bedank en om meer tevrede met die werk te wees.

Deur beklemtoning van die "kan doen aspek" (die derde aanname hierbo) is die "wil doen" - d.w.s. die motiveringsaspek verwaarloos. Die verskaffing van inligting oor die werk en oor die individue se eie vermoëns, vaardighede en motivering sal voornemende werkers in staat stel om self realistiese beroepskeuses te maak. Werkertevredenheid sal ook verbeter en arbeidsomset en afwesigheid sal afneem.

\section{Werkontwerp en werkverruiming (d.i. werkvergroting en -verryking)}

Die standaardisasie van werkmetodes en van poste geniet steeds baie aandag. Dit lei daartoe dat werk ontwerp word om geskik te wees vir die vaardighede en vermoëns van die "gemiddelde mens". Die volgende stap is dan om na die "gemiddelde mens" te soek om die werk te doen. Lawler se navorsing dui daarop dat werk slegs 'n positiewe, groei-produserende ervaring kan wees, as die werk so ontwerp word dat dit kan aanpas by individuele verskille ten opsigte van vaardighede, behoeftes en vermoëns. Die stelling is gebaseer op navorsingsdata wat aantoon dat die "gemiddelde mens" beide gelukkiger en meer effektief is as hy verruimde werk verrig in teenstelling met die verrigting van die tradisioneel gestandaardiseerde, gespesialiseerde, herhalende werk. Navorsing dui egter ook daarop dat daar baie "nie-gemiddelde mense" is wat gelukkig is as hulle repeterende, vervelende tipe werk doen. Alhoewel daar volop aanduidings is dat werksverruiming tot hoër prestasie en tevredenheid lei, het dit ook tot gevolg dat sommige mense minder werkstevredenheid ervaar.

Die daarstelling van geïndividualiseerde werksituasies, as teenvoeter vir bogenoemde probleem, is moeilik, maar Lawler en sy medewerkers se navorsing het weë aangedui waarvolgens dit moontlik is om organisasies so te struktureer dat dit voorsiening maak vir plasing van individue wat byvoorbeeld 'n behoefte het aan verruimde werk en demokratiese toesighouding, asook individue wat voorkeur gee aan geroetineerde werk en outoritêre toesighouding. 'n Metode om dit te doen is die skepping van relatief outonome subeenhede wat verskil in leierskapstyl, klimaat, werkontwerp, ens.

Werksaktiwiteite en werkspanne word so ontwerp dat individue die geleentheid kry om die werk te doen waarvoor hulle die beste geskik is en die graagste wil doen. 'n Ander metode is die gebruik van werkmodules. Take word in werkmodules verdeel en werknemers word die geleentheid gegee om die take te verrig waaraan hulle voorkeur gee. Meeste van hierdie idees is reeds met groot sukses toegepas in bedryfsorganisasies, byvoorbeeld in die 
bekendste vervaardiger van ontbytkosse in die Verenigde State. 'n Volledig navorsingsverslag hieroor word tans deur Lawler voorberei.

\section{Leierskap}

Daar bestaan tans heelwat navorsingsgebaseerde aanduidings dat deelnemende bestuur, as dit vergelyk word met outokratiese leierskapsvorms, tot verhoogde motivering, werkstevredenheid en produktiwiteit lei. Dit is egter ook 'n voldonge feit dat deelnemende bestuur nie tot verhoging van motivering, tevredenheid en produktiwiteit van alle werknemers lei nie. Lawler en ander by die Universiteit van Michigan se navorsing dui daarop dat sommige mense outokratiese leiding verkies, dat die begeerte van werknemers om aan besluite deel te hê varieer na gelang van die tipe besluit, en dat mense verskil met betrekking tot hul vermoëns om deel te neem aan besluitnemingsaktiwiteite.

In bestuurderopleidingsprogramme word dit ook beklemtoon dat bestuurders almal oor dieselfde kam moet skeer. Navorsing dui egter daarop dat die leiers wat hulle leierskap "individualiseer", d.w.s. aanpas by die behoeftes van individue, die effektiefste bestuurders is. Dit vereis diagnostiese vaardighede en gedragsaanpassings ten opsigte van toesighoudingspraktyke - vermoëns wat aangeleer kan word deur die klem in bestuurderopleidingsprogramme te verander.

\section{Werksure}

Die jarelange gebruik om werksure te standaardiseer is 'n praktyk wat geen ruimte laat vir die individuele behoeftes, voorkeure en gesinsomstandighede van werknemers nie.

Die invoering van fleksiewe werksure, wat vinnig begin veld wen, is 'n voorwaartse stap in die individualisering van organisasies. Daar kan nog baie gedoen word om die stelsels uit te brei, byvoorbeeld om voorsiening te maak vir korter of langer werksweke. Sommige werknemers kan byvoorbeeld 40 uur per week werk, ander 20 of 10. Dit sal dit moontlik maak dat egpare 'n werk kan deel. Die gesamentlike instelling van die module konsep kan dit baie makliker maak om werksure te varieer omdat individue nou soveel modules kan werk waarvoor hulle kans sien. Lawler is van mening dat eksperimente soos fleksiewe werksure sal toeneem, nie alleen omdat dit beter voorsiening maak vir individuele voorkeure nie, maar ook omdat dit bydra om traagheid ("tardiness") - 'n groot probleem in meeste organisasies - die hoof te bied. 


\section{Opleiding}

Dit spreek vanself dat die implementering van die idees hierbo uiteengesit, voorafgegaan moet word deur 'n herwaardering van bestaande opleidingspraktyke. Baie van die bestaande bestuurderopleidingsmetodes, byvoorbeeld sensitiwiteitsopleiding en spanbouaktiwiteite is o.m. gerig op die oorbrugging van individuele verskille. Of dit suksesvol hierin is, is 'n ope vraag. Daar bestaan aanduidings dat die tipe opleiding tot gevolg het dat die omvang van individuele verskille vergroot. Mense verskil ook ten opsigte van hulle vermoëns om te leer uit ervarings soos T-groepe. Ook ten opsigte van opleiding om werksvaardighede te verbeter behoort daar nou meer aandag aan individuele leervermoëns gegee te word.

\section{SAMEVATTING}

Lawler erken dat dit op die oomblik nog nie duidelik is hoe sulke uiteenlopende tegnieke soos die instelling van werkmodules, kafeteriaplanne, fleksiewe werksure, aanpasbare leierskapstyle, ens. in die praktyk geïntegreer en geïmplementeer kan word nie. Hy is van mening dat daar nie noodwendig 'n konflik tussen die metodes is nie, maar ook nie dat hulle noodwendig sinergisties is nie. Dit is ook sekerlik so dat alle organisasies nie van hierdie metodes gebruik kan maak nie. Of die inwerkingstelling van slegs een van die bespreekte metodes op sigself probleme rakende vervreemding, ontevredenheid en lae moreel gaan verbeter is sterk te betwyfel. 'n Kombinasie van 'n aantal van hierdie metodes, geselekteer om by die behoeftes van die spesifieke organisasie aan te pas, kan egter besondere voordele inhou. Verskeie skrywers, onder meer Kahn (1974) het bewys dat organisasieontwikkeling in die ware sin, ook strukturele veranderinge en aanpassinge van die organisasie moet insluit. Die hier bespreekte metodes kan dus beskou word as waardevolle organisasieontwikkelingsinstrumente.

Lawler en sy medewerkers is natuurlik nie die enigste wetenskaplikes wat waardevolle bydraes oor die individualisering van organisasies gelewer het nie. Hulle maak egter wel deel uit van 'n klein groepie navorsers wat reeds met empiriese bewyse na vore kon kom om te bewys dat organisasies hul keuringspraktyke, vergoedingstelsels, werksure, leierskapstyle en werksontwerp kan verander ten einde beter voorsiening te maak vir die individuele behoeftebevrediging van werknemers om sodoende 'n werksomgewing te skep wat die werknemer geleentheid tot hoër werktevredenheid bied, hom motiveer om sy werk te doen en die organisasie meer effektief te maak. 
*Waar een van die mees fundamentele knelpunte in die hedendaagse Suid-Afrikaanse ekonomie lae produktiwiteit is en waar lae produktiwiteit in die eerste plek 'n mensprobleem is, behoort die bydraes van wetenskaplikes rondom die individualisering van organisasies nie geïgnoreer te word nie.

Die kennis en kundigheid bestaan. Wat egter nog moet bykom is die waagmoed en professionele instelling van vele verligte bedryfsleiers om dit in die praktyk toe te pas.

\section{OPSOMMING}

In Lawler se navorsingspublikasies word 'n wye verskeidenheid onderwerpe aangeroer. Sy basiese wetenskaplike belangstelling is egter werksmotivering en hoe dit menslike gedrag in die beroepswêreld beïnloed. Hy lê klem daarop dat motiverings- en werksontevredenheids-probleme veroorsaak word deur die feit dat organisasies ontwerp word vir die hipotetiese "gemiddelde persoon" en dat enige gegewe arbeidsmag oor min, indien enige, "gemiddelde" persone beskik. Die verskillende metodes wat voorgestel word om die organisasie te individualiseer word in hierdie artikel beskryf. Dit sluit nuwe benaderings en aanbevelings aangaande onderwerpe soos vergoeding en byvoordele, keuring, posontwerp en posverruiming, leierskap, werksure en opleiding in.

\section{VERWYSINGS}

American Scientist,- Julie 1975.

Kahn, R.L. 1974. Organizational development. Some problems and proposals. The Journal of Applied Behavioral Science, 10(4), 485-504.

Lawler, E.E. III. 1963. Age and authorship of citations in selected psychological journals. Psychological Reports, 13, 537.

Lawler, E.E. III. 1965a. Secondary reinforcement value of stimuli associated with shock reduction. Quarterly Journal of Experimental Psychology, 17, 57-62.

Lawler, E.E. III. 1965b. Should managers' compensation be kept under wraps? Personnel, 42, 17-20.

Lawler, E.E. III. 1966a. Ability as a moderator of the relationship between job attitudes and job performance. Personnel Psychology, 19, 153-164.

Lawler, E.E. III. 1966b. The mythology of management compensation. California Management Review, 9, 11-22.

Lawler, E.E. III. 1967a. Post-doctoral training for industrial psychologists. The Industrial Psychologist, 4, 34-40.

Lawler, E.E. III. 1967b. How much money do executives want? Trans-Action, 4, 23-29.

Lawler, E.E. III. 1967c. Secrecy about management compensation: Are there hidden costs? Organization Behavior and Human Performance, 2, 122-142.

Lawler, E.E. III. 1968a. A correlational-causal analysis of the relationship between expectancy attitudes and job performance. Journal of Applied Psychology, 52, 462-468.

\footnotetext{
* Redaksionele byskrif 
Lawler, E.E. III. 1968b. Effects of hourly overpayment on productivity and work quality. Journal of Personality and Social Psychology, 10, 306-314.

Lawler, E.E. III. 1968c. Equity theory as a predictor of productivity and work quality. Psychological Bulletin, 70, 596-610.

Lawler, E.E. III. 1971a. The changing role of industrial psychology in university education: A symposium. Professional Psychology, 2, 2-22.

Lawler, E.E. III. 1971b. Pay and Organizational Effectiveness: A Psychological View. New York: McGraw-Hill.

Lawler, E.E. III. 1972. Secrecy and the need to know. Chapter in Tosi, H., House, R., and Dunnette, M.D. (eds.) Managerial Motivation and Compensation. East Lansing: Michigan State, University Press, pp.362-371.

Lawler, E.E. III. 1973. Individualizing organizations: A need emphasis in organizational psychology. Paper read at APA convention, Montreal, August, 1973.

Lawler, E.E. III. 1974a. For a more effective organization - Match the job to the man. Organizational Dynamics, 3(1), 19-29.

Lawler, E.E. III. 1974b. The individualized organization: Problems and promise. California Management Review, 17(2), 31-39.

Lawler, E.E. III. And Hackman, J.R. 1969. The impact of employee participation in the development of pay incentive plans: A field experiment. Journal of Applied Psychology, 53(b), 467-471.

Lawler, E.E. III. And Hackman, J.R. 1972. Corporate profits and employee satisfaction:

Must they be in conflict? California Management Review, 14, 46-55.

Lawler, E.E. III., Hackman, J.R. and Kaufman, S. 1973. Effects of job redesign: A field experiment. Journal of Experimental Social Psychology, 3, 49-62.

Lawler, E.E. III., Kuleck, W.J., Rhode, J.G. and Sorensen, J.E. 1975. Job choice and post decision dissonance. Organizational Behavior and Human Performance, 13, 133- 145.

Lawler, Carol O. and Lawler, E.E. III. 1965. Color-mood association in young children. Journal of Genetic Psychology, 107, 29-32.

Lawler, E.E. III. And O'Gara, P.W. 1967. The effects of inequity produced by underpayment on work output, work quality and attitudes towards the word. Journal of Applied Psychology, 51, 403-410.

Lawler, E.E. III. and Porter, L.W. 1963. Perceptions regarding management compensation. Industrial Relations, 3, 41-49.

Lawler, E.E. III. and Porter, L.W. 1966. Predicting managers' pay and their satisfaction with their pay. Personnel Psychology, 19, 363-373.

Lawler, E.E. III. and Porter, L.W. 1967a. The effects of performance on job satisfaction. Industrial Relations, 7, 20-28.

Lawler, E.E. III. and Porter, L.W. 1967b. Antecedent attitudes of effective managerial performance. Organizational Behavior and Human Performance, 122-142.

Lawler, E.E. III., Porter, L.W. and Tannenbaum, A. 1968. Managers' attitudes toward communication episodes. Journal of Applied Psychology, 52, 432-439.

Lawler, E.E. III. and Suttle, L. 1973. Expectancy theory and job behavior. Organizational Behavior and Human Performance, 9, 482-503.

Porter, L.W. and Lawler, E.E. III. 1964. The effects of "tall" vs. "flat" organization structures on managerial job satisfactions. Personnel Psychology, 17, 135-148.

Porter, L.W. and Lawler, E.E. III. 1965. Properties of organization structure in relation to job attitudes and job behavior. Psychological Bulletin, 64, 23-51.

Porter, L.W. and Lawler, E.E. III. 1968a. What job attitudes can tell us about employee motivation. Harvard Business Review, 46(1), 118-126. 
Porter, L.W. and Lawler, E.E. III. 1968b. Managerial Attitudes and Performance. Homewood, Illinois: Irwin-Dorsey.

Porter, L.W. and Lawler, E.E. III., and Hackman, J.R. 1975. Behavior in Organizations. New York: McGrawHill.

Scheflen, K.C., Lawler, E.E. III., and Hackman, J.R. 1971. The long-term impact of employee participation in the development of pay incentive plans: A field experiment revisited. Journal of Applied Psychology, 55(3), 182-186.

Wood, I. and Lawler, E.E. 1970. The effects of piece rate overpayment on productivity. Journal of Applied Psychology, 54, 234-238. 